\title{
EDUCAR DESDE LA EXPERIENCIA ÉTICA DEL OTRO
}

\section{EDUCATING FROM THE ETHICAL EXPERIENCE OF THE OTHER}

\section{Pedro Ortega Ruiz ${ }^{1}$}

Director Ripal, Colectivo Iberoamericano de

Pedagogía de la alteridad

España

portega@um.es

\section{RESUMEN}

La antropología y la ética atraviesan de principio a fin la acción educativa. Son sus referentes necesarios. La educación, al igual que la ética, es un encuentro con el otro que nos demanda acogida y reconocimiento desde la autoridad de la vulnerabilidad de su rostro. Toda acción educativa, al igual que la respuesta ética, es singular, original e irrepetible, por lo que nunca es extrapolable a otros individuos o situaciones. Constituye un nuevo nacimiento, el comienzo de algo nuevo. Ello exige no solo un modo distinto de pensar la educación, sino también un modo

1 Director Ripal, Colectivo Iberoamericano de Pedagogía de la alteridad España https://orcid.org/0000-0002-3882-0544 portega@um.es distinto de llevarla a la práctica, una nueva praxis. Esta encuentra en la narración de la experiencia de vida de cada educando no solo la estrategia más adecuada, sino el contenido mismo de la acción educativa. El comienzo de algo nuevo, el nacimiento de una nueva criatura son las figuras que mejor describen la educación como acto y como proceso.

\section{PALABRAS CLAVE:}

Educación, antropología, ética, narración, experiencia, nuevo nacimiento.

\section{ABSTRAC}

Anthropology and ethics go through educational action from beginning to end. They are their 
necessary references. Education, like ethics, is an encounter with the other that demands welcome and recognition from the authority of the vulnerability of its face. All educational action, like the ethical response, is unique, original and unrepeatable, so it is never extrapolated to other individuals or situations. It constitutes a new birth, the beginning of something new. This requires not only a different way of thinking about education, but also a different way of putting it into practice, a new practice. This is found in the narration of the life experience of each student not only the most appropriate strategy, but the very content of the educational action. The beginning of something new, the birth of a new creature are the figures that best describe education as an act and as a process.

\section{KEYWORDS:}

Education, anthropology, ethics, narration, experience, new birth.

\section{INTRODUCCIÓN}

Compadecerse del otro, sentir como propio el sufrimiento y el dolor del otro, es una conducta que nace de las entrañas, no de la razón. Cómo yo puedo sentir como mío el sufrimiento del otro, cómo su necesidad pueden convertirse en algo mío, es algo "misterioso". "Ese proceso es, lo repito, misterioso: pues es algo de lo que la Razón no puede dar ninguna cuenta inmediata y cuyos fundamentos no se pueden averiguar por vía de la experiencia. Y, no obstante, es cotidiano", afirma Schopenhauer en su obra: Los dos problemas fundamentales de la ética. Por qué unos responden acogiendo al necesitado y otros "pasan de largo", ignorando al que está hundido en el dolor, no tiene fácil respuesta. La ética no se atiene a argumentos de la razón, la sobrepasa. Compadecerse y hacer propia la causa del otro entra en un ámbito que no responde a las categorías que gobiernan, a diario, nuestra conducta. Los humanos somos animales de la razón. Esta característica es la que nos define y nos distingue de los otros animales. $Y$ en función de ella juzgamos nuestro comportamiento: si se atiene o no a la razón. Esta manera de proceder olvida que "las raíces de la cabeza están en el corazón”, como dice Ortega y Gasset. Razón y sentimientos se entrecruzan y se amalgaman en nuestra conducta, aún en aquella que a simple vista aparece más ligada a la razón o al sentimiento. Zubiri lo expresa en estos términos en su obra Inteligencia sentiente: "El sentir humano y la intelección no son dos actos numéricamente distintos, cada uno completo en su orden, sino que constituyen dos momentos de un solo acto de aprehensión sentiente de lo real: es la inteligencia sentiente (...) Inteligir es un modo de sentir, y sentir es en el hombre un modo de inteligir".

\section{El ámbito de la ética}

En el ser humano hay una brecha, una zona desprotegida, a la intemperie, que rompe con la lógica de la razón: el ámbito de la ética (no la moral), el proceder contra toda lógica racional. Desde la ética, solo se justifica una conducta si se tiene en cuenta el bien del otro, a pesar de todo. Es el otro, en su necesidad, quien legisla y ordena. Es la experiencia del otro sufriente, como totalmente otro, la que se me impone, la que me hace responsable de él sin que pueda decidir aceptarlo o rechazarlo. Esta ruptura o abandono del bien propio obliga inevitablemente al ser humano a ser dependiente, rehén del otro en su misma identidad humana. Soy sujeto cuando me siento atado al otro con una responsabilidad que no me la puedo quitar de encima, que ni la he buscado ni procede de un acto de mi conciencia. "No he hecho nada y siempre he estado encausado, perseguido. La ipseidad dentro de su pasividad sin arjé de la identidad es rehén. El término Yo significa heme aquí, respondiendo de todo y de todos", escribe Levinas en su obra magna: De otro modo que ser o más allá de la esencia. La ética (responder del otro) es una dimensión constitutiva del 
hombre, forma parte de su estructura radical. Los humanos somos seres para el otro, y nos "explicamos" como humanos solo desde el otro. "Yo estoy "en sí" por los otros (...) El Sí mismo es Sujeto; está bajo el peso del universo como responsable de todo", sigue afirmando Levinas en la obra antes citada. La ética (responsabilidad) "es la estructura esencial, primera, fundamental, de la subjetividad..., (la ética) no viene a modo de suplemento de una base existencial; es en la ética... donde se anuda el nudo mismo de lo subjetivo", afirma Levinas en: Ética e infinito. La subjetividad, en Levinas, no es autoafirmación, sino sujeción al otro que me singulariza y distingue al asignarme la tarea irrenunciable de acogerle y socorrerle, a la vez que me da la orden: "No me dejarás morir". La subjetividad no es un para sí, es un para el otro. El otro se resiste a ser poseído, asimilado por el Yo. Levinas lo expresa en estos términos en su obra Totalidad e infinito. Ensayo sobre la exterioridad: "El rostro se niega a la posesión, a mis poderes. En su epifanía, en la expresión, lo sensible aún apresable se transforma en resistencia total a la aprehensión. Esta mutación solo es posible por la apertura a una dimensión nueva ... La expresión que el rostro introduce en el mundo no desafía la debilidad de mis poderes, sino mi poder de poder". ¿Qué es lo que he hecho para ser de golpe deudor del otro?, se pregunta Levinas. $Y$ responde: "El prójimo me emplaza antes de que yo le designe, lo cual es una modalidad no del saber, sino de una obsesión $y$, con relación al conocimiento, un gemido de lo humano totalmente otro. El conocer siempre puede convertirse en creación y aniquilamiento, el objeto que se transforma en concepto puede convertirse en resultado... Estoy como ordenado desde fuera, traumáticamemnte dirigido... sin poder preguntar:... ¿de dónde le viene el derecho de dirigirme? ", escribe en su obra: $D e$ otro modo que ser o más allá de la esencia.
Este modo de entender la antropología y la ética rompe con la concepción autónoma, autosuficiente del hombre, instalada en el pensamiento occidental, que ha impregnado el discurso pedagógico y la praxis educativa. Una antropología y una ética en las que "el triunfo del ser es el triunfo del señor único que quita a los esclavos su voz propia, pero que paradójicamente, necesita de los esclavos para afirmarse como señor de ellos", escribe Pintor Ramos en su introducción a la obra de Levinas antes citada.

\section{La ética es compasión}

Vivir éticamente es tener puesta la mirada en el otro para responder a su demanda; es oír, prestar atención a la voz del otro que llevamos dentro; el otro del que no nos podemos separar. "Se trata de decir la identidad misma del yo humano a partir de la responsabilidad, es decir, a partir de esa posición o de esa deposición del yo soberano en la conciencia de sí, deposición que, precisamente, es su responsabilidad para con el otro. La responsabilidad es lo que, de manera exclusiva, me incumbe y que, humanamente, no puedo rechazar", escribe Levinas en: Ética e infinito. La ética es "obedecer" al mandato inapelable del otro. Pero esta respuesta es siempre imprevista porque la presencia del otro necesitado acontece sin previo aviso. Es un encuentro, un acontecimiento inesperado que nos sorprende y nos "trastorna" porque hemos de hospedar a alguien con el que no habíamos contado. Por ello, no nos podemos acostumbrar a vivir éticamente, a la respuesta compasiva. Estar pendiente del otro, sentirse rehén del otro complica la vida hasta límites insospechados. $Y$ no podemos situarnos al margen de la ética si no queremos poner en riesgo nuestra misma identidad como humanos. Es nuestra servidumbre $\mathrm{y}$, paradójicamente, nuestra "grandeza". La vida humana (ética) se vive desde la "obediencia y sumisión" (en sentido levinasiano) al otro afirmada siempre y 
en cualquier condición, porque nadie deja de ser "señor" (sí mismo) en cualquier circunstancia. "Señorío" que es negado en la sociedad del alejamiento y la indiferencia. "Casi sin advertirlo, nos volvemos incapaces de compadecernos ante los clamores de los otros, ya no lloramos ante el drama de los demás ni nos interesa cuidarlos, como si todo fuera una responsabilidad ajena que no nos incumbe", escribe el Papa Francisco en su Exhortación Apostólica "La alegría del evangelio".

La condición de rehén no es un "accidente" sobrevenido al sujeto ya constituido, por el contrario, es la condición para su misma existencia, y la condición de la existencia de la ética: "Es por la condición de rehén como puede haber en el mundo piedad, compasión, perdón y proximidad, incluso lo poco que de ello se encuentra, incluso el simple "usted delante, señor". La incondición de rehén no es el caso límite de la solidaridad, sino la condición de toda posible solidaridad", escribe Levinas en: De otro modo que ser o más allá de la esencia.

La ética es un encuentro con el otro, un acontecimiento que se resuelve en la acogida, en el hacerse cargo del otro, como el buen samaritano; es plena disposición (heme aquí) ante la presencia vulnerable del otro. Esta experiencia original, única, es una manifestación (epifanía) del otro en la vulnerabilidad de su rostro. En adelante, ya nada será igual para ambos, el que acoge y el acogido. Han entrado en una nueva forma de vida del uno para el otro "de gratuidad total, que rompe con el interés; un para de la fraternidad humana al margen de todo sistema preestablecido", escribe Levinas en: De otro modo que ser o más allá de la esencia. Vivir éticamente significa estar pendiente no de qué "debo hacer", sino de preguntarse "de quién soy prójimo"; no es la obligación de responder por un imperativo formal, sino por la "autoridad" de la persona concreta necesitada que me demanda una respuesta inapelable; es la imposibilidad de cerrar los oídos a la voz interior que nos dice y nos manda: "No Matarás" al otro que sale a tu encuentro. "La ética se hace con los pies en la tierra, y tiene mucho que ver con las situaciones reales de la vida de la gente. No es privativa de aquellos que son capaces de argumentar, con razones sólidas, lo que es bueno o malo, acudiendo a principios abstractos que nada tienen que ver con las "otras" razones, cargadas de sentimiento, que nos mueven a aliviar el dolor y el sufrimiento del próximo o prójimo, ese alguien histórico con el que tenemos una deuda pendiente: responderdeél", heescritoen unaobra reciente: A la intemperie Conversaciones desde la pedagogía de la alteridad. Schopenhauer lo expresa en estos términos en la obra: Los dos problemas fundamentales de la ética, antes citada: "...el verdadero impulso a la justicia y la caridad...tiene que ser algo que requiera poca reflexión y aún menos abstracción...y que, independientemente de la formación intelectual, hable a todos incluido el hombre más rudo, se base meramente en la comprensión intuitiva y se imponga inmediatamente a partir de la realidad de las cosas". Es una ética material que se construye, día a día, en las distintas situaciones en las que el ser humano se ve interpelado, aquí y ahora, por el otro ultrajado y necesitado. Así la entienden Horkheimer, Adorno y Levinas. La ética es denuncia y resistencia al mal histórico de este mundo; surge de la experiencia de sufrimiento del otro y se traduce en compasión y compromiso para transformar las situaciones injustas. No es la aspiración a una vida feliz situada más allá de la historia concreta de cada hombre o mujer. Tampoco busca el consuelo como huida o escape de la injusticia y la opresión. Es "el anhelo de que la injusticia que atraviesa este mundo no tenga la última palabra", escribe Horkheimer en su obra: Anhelo de justicia. La ética, más que discurso o argumento, es, ante todo, praxis, un quehacer compasivo. 
Pero la ética no nos libra de la perplejidad e incertidumbre en el camino a seguir; no nos despoja de nuestra condición de nómadas, nunca afincados a un territorio, ni nos garantiza la seguridad de una respuesta acertada. Nos vemos, con frecuencia, obligados a elegir el camino "equivocado" a juicio de la razón, y no pocas veces contra las normas socialmente establecidas. Vivir éticamente es remar contra corriente, con el viento en contra; es estar en permanente vigilia, nunca en reposo, porque el otro se nos presenta sin previo aviso. La ética no nos asegura la paz de la conciencia, la tranquilidad del deber cumplido. Siempre queda un camino por recorrer, la inquietud de una deuda pendiente con el otro. Es la atadura que nos liga irremediablemente al otro. La ética es inseparable del riesgo, de la incertidumbre. No nos lleva a meta alguna previamente fijada. Todo está por construir, todo es provisional como la "circunstancia" (situación) que envuelve la vida misma; no hay cánones prefijados que prescriban una conducta; la tenemos que realizar "a tientas", sin más argumentos que aquellos que brotan de los sentimientos de compasión. En todo momento nos sentimos "abandonados" a la improvisación, a la aventura, al riesgo de no ser lo suficientemente compasivos. No se es ético (compasivo) de una vez para siempre. La ética, como respuesta compasiva, no es un estado o "modo de ser", es la provisionalidad misma de la respuesta al otro necesitado. No debemos, por tanto, pensar en consistencias o hábitos adquiridos, que garanticen o faciliten una conducta ética, como objetivos de la educación.

\section{La educación es un nuevo nacimiento}

Toda antropología lleva a una ética, y toda ética está referenciada a una antropología. Del mismo modo, la educación está también vinculada a una antropología y a una ética determinada. La atraviesan de principio a fin y se hacen presentes en cada uno de sus actos. En educación nada se explica sin la referencia a un punto de partida (presupuestos) que da soporte a todo el proceso educativo. Si la ética es una repuesta compasiva a un sujeto singular, en una situación concreta de necesidad, la educación, como la ética, es también una experiencia singular, un encuentro único e irrepetible con el otro necesitado de acogida y acompañamiento. Este encuentro con el otro (educador y educando) marca el comienzo de algo nuevo, el nacimiento de una nueva vida, el depósito de una semilla que empieza a germinar. Es una revelación, la epifanía de algo que estaba escondido y que ha salido a la luz. Es un acontecimiento único que lo trastoca todo, que pone en marcha todos los resortes de una nueva existencia.

Al igual que no sabemos por qué y cómo se produce la respuesta compasiva hacia el otro necesitado, tampoco sabemos cómo se produce y por qué la acción de acogida y acompañamiento al otro en un proceso educativo, es decir, cómo y dónde se produce el encuentro ético entre educador y educando. Podemos establecer las "condiciones" para que dicho encuentro se produzca, pero la experiencia del mismo no está a nuestro alcance. ¿Qué ha acontecido en el educador que le ha hecho salir de sí para acoger al otro (educando)?, ¿cómo ha influido en el educador la acogida al otro?, ¿qué ha acontecido en el educando al confiar en el otro (educador), dejarse acoger y acompañar por él?, ¿qué ha supuesto en la vida del educando la presencia ética del educador?, ¿cómo discurre el proceso de acogida y acompañamiento al educando? Solo podemos afirmar que en la educación, como acto y como proceso, se produce un encuentro, un acontecimiento ético que marca el comienzo de algo nuevo, la experiencia de una nueva existencia, el "nacimiento de una nueva criatura por la que el mundo se renueva sin cesar", como afirma $\mathrm{H}$. Arentdt. Pero al igual que en la ética, nos seguimos preguntando cómo y por qué se produce este encuentro único e irrepetible con el otro. En una palabra: qué se esconde debajo de cada acción educativa. 
La educación, como acto y como proceso, conlleva el nacimiento de algo nuevo. Nunca puede ser la repetición de lo ya dado. Cada acción educativa es para el educando una nueva situación, una nueva ocasión de responder a la actitud de acogida del educador. En la educación acontece el "milagro" de la epifanía de un nuevo ser, una nueva experiencia que se manifiesta en una manera nueva, singular y única de realización del ser humano, aquí y ahora. Hasta ahora, esta experiencia era inédita, sucede por primera vez. Constituye una aportación nueva al mundo en construcción.

Estamos acostumbrados a explicar, con mayor o menor fortuna, los procesos de aprendizaje de conocimientos y destrezas. $Y$ tendemos a extrapolar, erróneamente, esta competencia a los procesos educativos, ignorando que estos, por su propia naturaleza, escapan a un control que lo harían extrapolable a otros procesos. La ética, en tanto que respuesta compasiva al otro necesitado, es siempre singular, única e irrepetible. Y la educación, como respuesta de acogida al otro, comparte con la ética esta característica de ser también una actuación singular, única, original, porque no hay, ni puede haberla, una acción educativa que sea igual para todos. Cada individuo vive en una circunstancia que le condiciona de un modo singular; y cada individuo interpreta su mundo también de un modo singular. El mundo en el que vivimos y la vida que conocemos es siempre un mundo y una vida interpretados.

Lo dicho hasta aquí nos debería llevar a los educadores y pedagogos a tratar la educación con "herramientas" distintas a las que se emplean en otros ámbitos del saber. En educación se nos escapa aquello que llevamos entre manos: el ser humano. En un proceso educativo (no instructivo) solo podemos asistir al nacimiento de algo inesperado que, hasta ahora, solo era promesa y empieza a ser realidad por el encuentro fortuito entre dos que se reconocen (educador y educando) en la salida de sí mismos para construir una nueva realidad: la experiencia del nacimiento de una nueva criatura, el comienzo de algo nuevo. Esta nueva realidad, por su carácter singular, original, reclama también un tratamiento singular $\mathrm{y}$ original.

Estas páginas, ajenas a las reglas de la Academia, quieren ser una llamada a una reflexión sobre lo que estamos haciendo o dejando de hacer en educación. Propugno, desde aquí, una pedagogía del nacimiento como forma de recibir a los que llegan a nuestro mundo y al suyo, siempre en construcción, desde la radical alteridad del otro nunca asimilable al yo; y una pedagogía del comienzo que incorpora y transforma lo antiguo para integrarlo en un nuevo proyecto de realización de cada ser humano, porque "los hombres, aunque han de morir, no han nacido para eso, sino para comenzar algo nuevo", dice H. Arendt. Pretendo promover un debate que saque al discurso pedagógico y a la praxis educativa de la rutina y del cansancio que provoca el "repetir siempre lo mismo". La novedad, lo nuevo, es inherente a la educación.

La pedagogía del nacimiento y del comienzo conlleva un cambio radical en la praxis educativa. Los "educadores" nos hemos comportado como si nuestros valores éticos, y su priorización, fuesen también los valores demandados por los educandos. Hemos proyectado sobre ellos nuestro ideal de vida sin prestar atención a los intereses y necesidades de aquellos a quienes pretendemos acompañar en su proyecto (no el nuestro) de realización personal. La escucha y atención al otro es el camino obligado para un encuentro con él en la realidad (experiencia) de su vida. Solo desde aquí, desde la experiencia de vida del otro, se inicia un proceso de acogida y acompañamiento al otro, un proceso educativo. La praxis heredada de una educación "por encargo", hecha a distancia, nos ha alejado de cualquier posibilidad de educar para 
convertirnos en instrumentos involuntarios de un solapado adoctrinamiento. Solo se educa cuando se escucha y acoge la palabra del otro "que nos trasciende como educadores y frente al cual tenemos la obligación de asumir una responsabilidad incondicional, más allá de todo contrato posible o reciprocidad", escriben Bárcena y Mélich, en su obra: La educación como acontecimiento ético. Solo se educa desde la experiencia distinta de cada educando. Este es un principio vertebrador de toda acción educativa. Es su punto de partida y de llegada. Ignorarlo, significa desconocer la esencia misma de toda educación.

\section{La experiencia, contenido educativo}

La pedagogía cognitiva ha centrado su actuación en el desarrollo del juicio moral como estrategia adecuada (y única) para promover y facilitar una conducta (respuesta) ética. Pero no es la fuerza de los argumentos de nuestra razón la fuente u origen de la responsabilidad (ética) hacia el otro. No nos compadecemos del otro porque hagamos sesudos razonamientos sobre la dignidad de la persona, sino por el "vuelco" interior que nos produce su situación de necesidad significada en su rostro herido. Es el otro el que nos conmueve interiormente y nos "empuja" a responder éticamente, no nuestros argumentos. La ética no tiene su origen en el yo que reconoce la dignidad del otro, sino en el otro, en su experiencia de necesidad. Es el otro el que nos convierte en una persona ética cuando nos compadecemos de él. La ética es siempre una respuesta a una experiencia de alguien concreto, necesitado de acogida y de reconocimiento; la respuesta a la demanda inapelable del otro.

¿Pero se puede enseñar a responder éticamente al otro necesitado? Si la respuesta ética, es decir compasiva, es siempre imprevista, original e irrepetible, se hace difícil aceptar el aprendizaje de "competencias" que capaciten al educando para responder habitualmente al otro necesitado en una situación concreta. El carácter singular, único e irrepetible de la respuesta compasiva escapa a toda posibilidad de adquirir una competencia específica para su realización. No somos "competentes" para una respuesta ética; la debemos improvisar constantemente. No somos competentes para la compasión. Levinas nos enseña en su obra: Ética e infinito cómo situarnos ante el otro como referente ético, no como objeto de conocimiento, que, en tal caso, entraría en el ámbito de los aprendizajes o competencias. "Cuando usted ve una nariz, unos ojos, una frente, un mentón, y puede usted describirlos, entonces usted se vuelve hacia el otro como hacia un objeto. ¡La mejor manera de encontrar al otro es la de ni siquiera darse cuenta del color de sus ojos! Cuando observamos el color de los ojos, no estamos en relación social con el otro. Cierto que la relación con el rostro puede estar dominada por la percepción, pero lo que es específicamente rostro resulta ser aquello que no se reduce a ella". El acceso ético al otro no es objeto de percepción o descripción, no es objeto de conocimiento. Éste siempre ha sido interpretado como asimilación. El conocimiento no nos pone en comunión con el otro, no nos acerca a lo verdaderamente otro, sigue afirmando Levinas en la obra antes citada. La mirada ética, por el contrario, entra en el ámbito de los afectos, de los sentimientos. "Una ética de la compasión no puede ser sino una ética de los afectos y no de los efectos, una ética de la afectividad y de la intimidad, no de las grandes respuestas establecidas de antemano, ni de los códigos deontológicos. Una ética de la compasión es una ética de la sensibilidad con el otro", escribe Mélich en: Ética de la compasión. Levinas resalta la importancia de la proximidad y del afecto en la significación ética del rostro: "Rostro que está cerca, contacto de una piel; rostro que se expresa como piel y piel en la que, incluso en la obscenidad, respira el rostro alterado", en su obra: De otro modo que ser o más allá de la esencia. 
Por ello, más que enseñar "competencias" o hábitos que faciliten una conducta ética, habría que promover en los educandos el desarrollo de actitudes de acogida al otro en sus circunstancias concretas; facilitar el desarrollo de la apertura al otro (empatía) que promueva el acercamiento al otro, y no considerarlo como un extraño que se cruza en su camino; promover el desarrollo de la sensibilidad para estar atentos a la necesidad del otro y situarse a su lado. Es decir, ver lo que el buen samaritano vio y no vieron el sacerdote y el levita del pasaje evangélico. Este tipo de "aprendizajes" requiere estrategias que se apartan del recurso al dilema moral o la adquisición de hábitos para una buena conducta. Más bien reclama acudir a la experiencia de vida de cada educando a través de la narración o el relato, y que sea esta experiencia la que se convierta en contenido y estrategia educativa. "La vida de cada uno de nosotros es un texto, una escritura de relaciones con el mundo que hemos heredado, un mundo biológico y cultural a la vez, así como también lo es con los otros y con nosotros mismos", escribe Mélich en la obra antes citada. Y encontraremos experiencias en las que el educando se muestre cerca del otro, situado a su lado, y otras de alejamiento e indiferencia. Todas le pertenecen por igual.

La narración nos desvela aquello que hay de recóndito en la experiencia de cada uno, lo que hemos sido y hemos vivido, lo que somos y lo que hoy vivimos. "En realidad, nuestras "historias" constituyen el resumen o el precipitado vital y narrativo de las sucesivas asociaciones de espacio y de tiempo que hilvanan el tejido de toda nuestra existencia humana", escribe Duch en su obra: Estaciones del laberinto. La narración es un libro que se abre para ser leído por otros. En ella la alteridad es despojada de su carácter genérico y abstracto para encarnarse en alguien concreto, con nombre y apellidos, con rostro, en expresión de Levinas, que éticamente espera der nosotros una respuesta responsable.
Y en esa lectura, la experiencia narrada ya no es solo mía, es también de los otros al ser evocada. En la narración la experiencia no se repite, se evoca, se hace presente en un nuevo contexto, y al evocarla, se le da nueva vida, es reinterpretada. La narración de la experiencia sitúa al educando en el centro de su proceso educativo. Es su experiencia, su vida contada y la de sus compañeros, no la experiencia y vida de unos modelos ideales, traídos de la leyenda y la literatura, la que se convierte en experiencia ética. Son experiencias cercanas, sujetas a contradicciones, que reflejan la vida real de individuos también reales. La experiencia en la educación deja de ser un mero recurso didáctico. Es un contenido educativo esencial. No es un viaje de ida y vuelta; es un "ir para quedarse ahí, en ella, y de ella aprender.

Lanarracióndelapropiaexperienciapuedeayudar a que el educando descubra la realidad de su vida, hecha, no pocas veces, de contradicciones del buen samaritano sensible al sufrimiento del otro, y del levita y del sacerdote que pasan de largo o apartan la vista del caído junto al camino. Ambas respuestas constituyen contenidos válidos para la educación en la responsabilidad. Aprendemos de aquellos que ponen en peligro su vida por salvar la de otros, y de aquellos que representan el desprecio o negación de la vida humana (pedagogía negativa). Acudir a la narración de la propia experiencia nos aleja de una enseñanza "libresca" de corto recorrido que ha inundado nuestras aulas con los resultados ya conocidos. Si prescindimos del relato de nuestra vida, de nuestras experiencias, no solo hacemos imposible la educación para una vida responsable (ética), haremos de la enseñanza una actividad para seres imaginarios. Conectar con la vida (experiencia) de cada educando implica estar presente en el aula para ayudar al educando a la construcción de su proyecto de vida, haciendo posible el comienzo de algo nuevo, el nacimiento de una nueva criatura. 


\section{Otro modo de educar}

Echo de menos una reflexión sosegada y rigurosa sobre "otro modo de pensar y hacer" la educación desde otros presupuestos que la alejen de una concepción idealista que ha prescindido de la urdimbre de la vida del ser humano en la que se juega, a diario, su existencia como humano. "Es hora ya de que quienes elaboran el discurso pedagógico oficial empiecen a tomar en serio el hecho de que el ser humano es un ser histórico, impensable fuera o al margen del aquí y del ahora", escriben Bárcena y Mélich en su obra antes citada. Se ha alimentado una filosofía de la educación que no ha encontrado el modo de hacer suya la situación (circunstancia) en la que vive cada educando; se ha pensado y actuado como si todos los educandos compartiesen los mismos intereses y aspiraciones, o perteneciesen a una misma realidad socio-cultural; se ha visto y tratado la educación como una herramienta imprescindible para el encaje del educando en el entramado social; se ha prestado más atención a las exigencias del mercado que a la necesidad de formar ciudadanos libres y responsables de lo que acontece en su comunidad; se ha perdido de vista al ser humano concreto, sujeto y protagonista de su proceso de formación; se ha pensado la tarea de educar como un simple proceso de socialización en el que priman intereses no pocas veces ajenos a las necesidades de cada educando concreto; se ha pensado la educación como repetición de lo dado y no como innovación y búsqueda de otros modos de estar en el mundo y hacerse cargo de él. Se ha olvidado que hemos venido a este mundo para cambiarlo y transformarlo, "para comenzar algo nuevo". Y hacer que este mundo nuestro sea mejor que el que hemos heredado es una tarea indeclinable de cada uno, no hay sustitución posible. En la educación empieza algo nuevo, algo inédito como forma original de estar en el mundo, y con él una nueva aportación a su construcción desde los parámetros de la justicia y la compasión.

Deberíamos hacer un esfuerzo por recuperar el sentido originario de la educación y alejarnos de su función instrumental-mercantilista en la que la sociedad del consumo la ha instalado. Recuperar la función formadora-educativa que va siempre unida a la ética como a su cordón umbilical. $Y$ no cualquier ética, sino a aquella que se pregunta constantemente por la suerte del otro: ¿de quién soy yo próximo? para hacerme cargo de él. "Si este mundo nos parece, en alguna medida "salvable", digno del hombre, no es por los descubrimientos científicotecnológicos, sino por aquellos hombres y mujeres que, desde la compasión con los más desfavorecidos y abandonados, arriesgan su vida por salvar la vida de los otros. $Y$ hacerla más humana", he escrito en la obra: $A$ la intemperie. Conversaciones desde la pedagogía de la alteridad, antes citada.

No hay educación si no hay libertad. $Y$ sin libertad no hay compasión. La ruptura que entraña la praxis compasiva con el orden establecido exige el ejercicio de la libertad. "Poner en relación la ética de la compasión con la libertad significa que "ser compasivo" es comprender que jamás estamos del todo atados a un lugar, a un principio, a una idea, a un partido; significa que somos en todo momento un poco extranjeros para nosotros mismos y para los demás, significa que no tenemos las cuentas claras con nuestro propio yo, con nuestra identidad, significa que hay una extrañeza que nos forma, nos conforma y nos deforma. Si no hay "deserción" de uno mismo y de la "ley" heredada, la compasión es imposible", escribe Mélich en su obra: Ética de la compasión. Una sociedad humanizada, a la altura del hombre, no es fruto solo de las estructuras sociales justas, sino de las relaciones de cordialidad y compasión que se establezcan entre sus ciudadanos. "El hombre de la obligación, incluso frente al demonio, solo deberá cumplir 
con su obligación", escribe Dietrich Bonhöefer en su obra: Ética. El propósito del "ajuste y del encaje" en el entramado social, sin la posibilidad de someterlo a crítica, contradice la esencia misma de la educación. Un individuo "formado" para el "ajuste" a la sociedad está incapacitado para la vida ética. $Y$ una sociedad que solo se mueve guiada por el cumplimiento de la ley se convierte en una sociedad a la que le faltan los lazos de la fraternidad y la solidaridad, el rostro humano que nos protege a todos de la frialdad de la indiferencia. La experiencia ética del otro, la dependencia del otro y no una supuesta "esencia" de lo humano es lo que establece el grado de humanidad o eticidad de los seres humanos. Sin el lazo que nos ata al otro, sin la compasión no hay vida humana.

\section{REFERENCIAS BIBLIOGRÁFICAS}

Bárcena, F. y Mélich, J. C. (2000) La educación como acontecimiento ético (Barcelona, Paidós)

Bonhöefer, D. (2000) Ética (Madrid, Trotta)

Duch, LI. (2004) Estaciones del laberinto Barcelona, Herder)

Horkheimer, M. (2000) Anhelo de justicia (Madrid, Trotta)

Levinas, E. (1987) Totalidad e infinito. Ensayo sobre la exterioridad (Salamanca, Sígueme)

Levinas, E. (2011) De otro modo que ser o más allá de la esencia (Salamanca, Sígueme)

Levinas, E. (2015) Ética e infinito (Madrid, Machado Edit.)

Mélich, J. C. (2010) Ética de la compasión (Barcelona, Herder)

Ortega, P. y Romero, E. (2019) A la intemperie. Conversaciones desde la pedagogía de la alteridad (Barcelona, Octaedro)

Schopenhauer, A. (1993) Los dos problemas fundamentales de la ética (Madrid, Siglo XXI)

Papa Francisco (2013) Exhortación Apostólica: La alegría del evangelio (Madrid, San Pablo Edit.)

Zubiri, X. (1998) Inteligencia sentiente (Madrid, Alianza) 